140812_105 5516 words

What students want: using a choice modelling approach to estimate student demand

\author{
Paula Sheppard ${ }^{1 *}$ \\ Richard Smith ${ }^{1}$ \\ ${ }^{1}$ London School of Hygiene \& Tropical Medicine, Keppel Street, London, WC1E 7HT, UK. \\ * Corresponding author paula.sheppard@1shtm.ac.uk Tel: +44(0)20 79588227
}

\begin{abstract}
Higher education institutions operate in an increasingly competitive global market, and require precise knowledge regarding the preferences of potential students. Traditional methods for evaluating what potential students look for in a degree tend to be descriptive, and while informative, do not assess the strength of students' preferences; how important they are relative to each other, and hence where efforts and investments may best be targeted. To do this, more statistically rigorous methods are required. We used a discrete choice experiment to estimate the relative importance of the attributes that inform student choice and also quantify these trade-offs in monetary terms using 'willingness to pay'. Using data from a UK postgraduate institution we illustrate how this method can be applied and can provide an accurate measure of student preferences as well as quantifying the trade-offs students are willing to make. Our results show that staff expertise, and flexibility of the teaching platform, were the attributes that students most highly value when choosing a postgraduate degree.
\end{abstract}

Key words: discrete choice experiment, stated choice, willingness to pay, student demand, higher education institution

\title{
Introduction
}

Higher education institutions increasingly need to meet students' needs more closely if they are to attract high quality applications (Department for Business Information and Skills, 2011; Mellors-bourne, Hooley, \& Marriott, 2014). Increases in fees and current fragile economic conditions mean that higher education institutions find themselves in an increasingly competitive market. To attract applications from the highest quality students, and to effectively compete with other higher education institutions, universities must accurately identify student needs, and design and deliver courses that fully satisfy student demand. Failure to meet student needs and increase student satisfaction will disadvantage any university that wants to compete in the growing service industry that higher education now is.

In the UK, postgraduate study has declined nationwide prompting the government, and other national bodies, to undertake research to identify the reasons for this trend (Mellors-bourne et al., 2014; Universities UK, 2013). The data collected in such research however is descriptive and therefore limited in scope. Data identifying what students expect from a degree, and from a university, are usually obtained by traditional survey methods where alumni and current students are asked about their overall satisfaction with the degree and the university (Elliott \& Shin, 2002). There are issues with this type of data collection; in particular there are problems with response rate bias, question ordering bias, the phrasing of the questions, the mode of collection, etc. (Peterson \& Wilson, 1992). Critically, this data does not provide a reliable 
indication of the relative strength of preference between critical elements affecting students' decisions, and thus guide more strategic development and investment.

The aims of this study are to identify (a) the attributes that students consider more important in their choice of degree program, and (b) how much students are willing to trade off certain attributes against others. To do this we used the 'discrete choice experiment' method, which offers a valuable addition to these traditional descriptive methods. We first briefly describe discrete choice experiments and then present the methods and results from our example.

\section{Discrete choice experiments}

A discrete choice experiment is an attribute-based measure of relative value, where attributes are the properties of a product or service. It is based on classic random utility theory and Lancaster's concept of value (Louviere, Hensher, \& Swait, 2000). Attributes are assigned levels (e.g. prices) although these can also be qualitatively different features (e.g. colours). The underlying assumption is that individuals make rational choices based on the attributes that make up the product, in a way that maximises utility, and by making trade-offs between the attributes (Kjaer, Bech, Gyrd-Hansen, \& Hart-Hansen, 2006). In the application of a discrete choice experiment, individuals are asked to make a series of choices between alternative hypothetical products, or scenarios, made up of a number of attributes and their levels. The resulting choices reveal the underlying utility function of the product. A discrete choice experiment is particularly useful when revealed preferences (actual behaviour) are unavailable or difficult to measure.

Discrete choice experiments are stated choice models, used because: (a) it is usually not financially feasible to create a product and then to test consumer preference for that product; and (b) consumer behaviour cannot inform us about the relative value of the traits that make up a product, nor the monetary value of the individual attributes that are component of the product. The advantage of using a discrete choice experiment is that it is possible to identify which components (attributes) make up the ideal scenario as opposed to simply which overall scenario is preferred in a more qualitative sense. Discrete choice experiments also make it possible to quantify the relative value of each attribute as participants are forced to make trade-offs when choosing between hypothetical scenarios. Although they are popular in various economics fields (Chomitz, Setiadi, Azwar, \& Wadiyarti, 1999; Kolstad, 2011; Kruk et al., 2010) and among market researchers (Earnhart, 2002; Hensher, Rose, \& Greene, 2005), they have been little applied to other areas of policy research.

Determining the product attributes and assigning appropriate levels is essential for designing and conducting a successful experiment. Misidentification of the attributes and levels will undermine the validity of the results. It is highly recommended to use qualitative methods to discover what these are: reviewing the literature, conducting focus groups and personal interviews, or open-ended questionnaires are suggested avenues for revealing descriptions of what people want from a certain product or service, and in the specific case here the student satisfaction surveys often carried out can also be used to good effect (Coast \& Horrocks, 2007; Kløjgaard, Bech, \& Søgaard, 2012). It is also worth pilot testing the experimental design both qualitatively and quantitatively to ensure the choice sets are properly understood, not too cognitively demanding, and that the length of the questionnaire (number of choices presented) is appropriate to avoid mental fatigue (Bridges et al., 2011; Kløjgaard et al., 2012). Ideally the final questionnaire should present choice sets that incorporate the most important attributes, sensible levels, but must also represent realistic 'real life' scenarios. Discrete 
choice experiments can rarely incorporate all of the attributes revealed by the qualitative research and the researcher must identify those which seem most important and also those that have practical application for the implementation of policy. Ideally there should also be one continuous attribute (e.g. fees) in order to calculate willingness to pay estimates: monetary values of the attributes.

Once the attributes have been identified, and allocated levels, they need to be drawn up into choice sets which will go into the questionnaire. Having even a modest number of attributes and levels is usually too many to create a fully factorial design (where all possible combinations are used). Instead, a fractional factorial design can be implemented using an orthogonal array. Most statistical software programmes can handle this and provide an orthogonal design, where the variables are uncorrelated (or have very low correlations); see (Kuhfeld, 2010) for detailed instructions on how to design the survey using SAS® software. The attribute levels should also be balanced, where they appear an equal number of times throughout the questionnaire (or as close to), and have minimum overlap, so there is no repeat of the same level of a single attribute within a single choice set. Finally the choices have to be realistic and make logical sense. If the choices are too cognitively dissonant, individuals will cease to make rational trade-offs (World Health Organization [WHO], 2012).

\section{Estimating factors influencing student demand using a discrete choice experiment}

We conducted a discrete choice experiment at the London School of Hygiene \& Tropical Medicine to estimate student demand for master's degrees and to establish which qualities (attributes) students look for in a degree and an institute, as well as how important each attribute is in relation to others. The London School of Hygiene \& Tropical Medicine is a postgraduate institution in London, UK and offers thirty taught master's degree courses in various health-related disciplines. Ethics approval to conduct this experiment was obtained from the School's Ethics Committee.

We collected data from current students and alumni in a student satisfaction survey. Students were asked 'What were the key factors that led you to choose to come to the School?' allowing for open-ended responses. The answers showed that the most popular responses were: the expertise of the teaching staff, the reputation of the School, appropriateness of the course, that the School is London-based, and that the School was personally recommended. Figure 1 shows the distribution of these attributes, all of which were mentioned more than ten times.

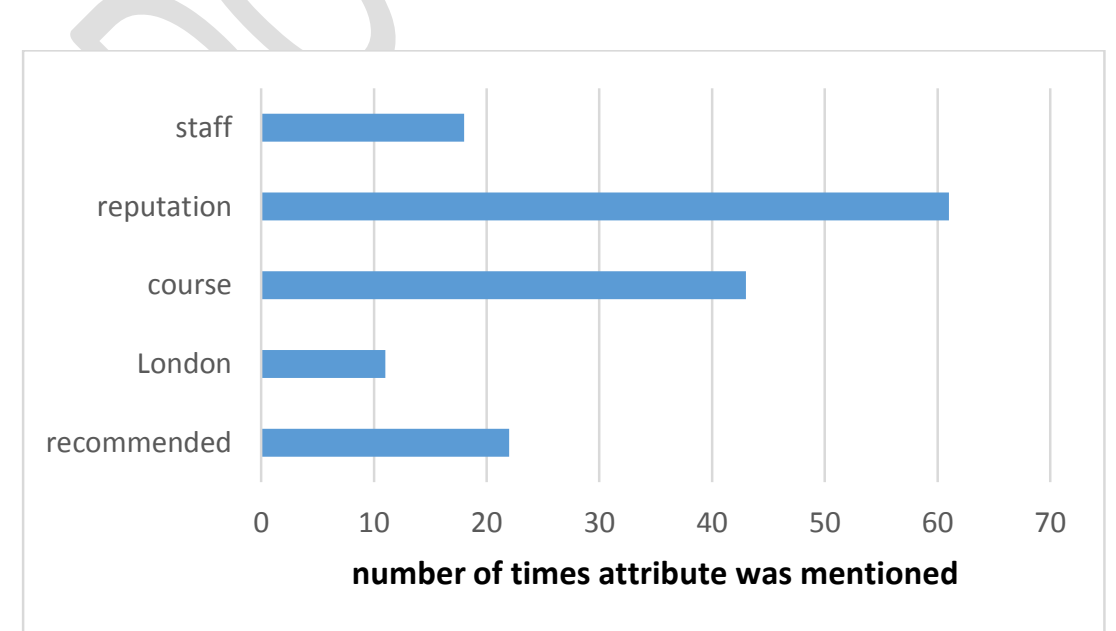

Figure 1: Most commonly mentioned attributes 
Attributes for the discrete choice experiment were derived from the results of this research, and then modified to include attributes that the School is able to manipulate. For example, while fees did not appear to be a very common attribute, this attribute was included in the study to measure the trade-offs made in monetary value. Conversely, there is little the School can do to control an attribute associated with being in London. Analysis of the data also indicated that it was likely that reputation and recommendations were closely associated with staff. The final attributes that were chosen were therefore: the calibre of the teaching staff, the flexibility of the degree syllabus, the teaching platform, the duration of the course, and the fees. The levels were determined by options that would be possible for the School to implement. For example the School already has a full time and part time option but if students showed a preference for the part time option to be extended for more than two years, it would be possible for the School to offer a degree that could be completed over any length of time up to five years. The attributes, and their levels, are shown in Table 1, worded exactly as presented in the survey. We developed a balanced, orthogonal, fractional factorial design using SAS ${ }^{\circledR}$ software (Kuhfeld, 2010) and personally checked the choice sets to ensure they presented plausible and realistic scenarios. The survey was distributed online and was programmed so that the choice-set questions were randomised for each respondent to minimise question ordering bias. We held the first and last questions constant as they were identical, to check for response consistency.

Table 1: Attributes and levels that were used in the questionnaire

\begin{tabular}{|c|c|c|c|}
\hline Attribute & Level 0 & Level 1 & Level 2 \\
\hline $\begin{array}{l}\text { The calibre of the } \\
\text { teaching staff }\end{array}$ & $\begin{array}{l}\text { You will primarily be } \\
\text { taught by more junior } \\
\text { members of staff }\end{array}$ & $\begin{array}{l}\text { You will be taught by } \\
\text { staff at all levels, } \\
\text { including by senior } \\
\text { leaders in the field }\end{array}$ & \\
\hline $\begin{array}{l}\text { The flexibility of the } \\
\text { degree syllabus }\end{array}$ & $\begin{array}{l}\text { The Master's degree } \\
\text { has some fixed core } \\
\text { modules and a choice } \\
\text { of other optional }\end{array}$ & $\begin{array}{l}\text { You have the freedom } \\
\text { to choose all the } \\
\text { modules in the } \\
\text { Master's degree }\end{array}$ & \\
\hline $\begin{array}{l}\text { The teaching } \\
\text { platform }\end{array}$ & $\begin{array}{l}\text { All modules are taught } \\
\text { in a face-to-face } \\
\text { classroom setting }\end{array}$ & $\begin{array}{l}\text { You have the option to } \\
\text { have some modules } \\
\text { taught in the } \\
\text { classroom and others } \\
\text { by online learning }\end{array}$ & \\
\hline Fees & $£ 9,000$ & $£ 12,000$ & $£ 15,000$ \\
\hline $\begin{array}{l}\text { Duration of the } \\
\text { degree }\end{array}$ & Full time (1 year) & Part time (2 years) & $\begin{array}{l}\text { Part time (up to } 5 \\
\text { years) }\end{array}$ \\
\hline
\end{tabular}

\section{Sample}

The survey targeted UK-based participants as the School was primarily interested in home students' preferences. It was easiest therefore to conduct the survey online and distribute it via a crowd-sourcing agency, social networking sites, student unions, and from Guys and St 
Thomas's Trust to target their professional staff. This provided a final sample of 206 participants. Table 2 shows the demographic breakdown of the complete sample.

Table 2: Demographic composition of participants. Percentages do not always total 100 due to rounding

\begin{tabular}{lrr}
\hline Demographic & n (206) & \% \\
\hline Sex & & \\
Male & 87 & 42.2 \\
Female & 116 & 56.3 \\
Missing & 3 & 1.5 \\
$\quad$ Age group & 122 & 59.2 \\
18 to 30 & 65 & 31.6 \\
30 to 45 & 19 & 9.2 \\
45 plus & & \\
$\quad$ Employment status & 104 & 50.5 \\
Employed full-time & 20 & 9.7 \\
Employed part-time & 51 & 24.8 \\
Student full-time & 8 & 3.9 \\
Student part-time & 19 & 9.2 \\
Other & 4 & 1.9 \\
Missing & & \\
$\quad$ UK country & 181 & 87.9 \\
England & 4 & 1.9 \\
Northern Ireland & 13 & 6.1 \\
Scotland & 8 & 3.9 \\
Wales & & \\
\hline
\end{tabular}

\section{Quantitative analysis}

A conditional logit model was used to analyse the data as this can account for groups within individuals: data for each choice set are stored on two lines (WHO, 2012). The dependant variable is binary (university A or B) and so odds ratios can be calculated. These should be interpreted as odds ratios lower than 1 indicating lower odds of choosing that response (i.e. a lower preference) and higher than 1, a stronger preference. Preparation of the data, and all statistical analyses were performed using Stata v. 13®.

\section{Results}

The results for the main effects are presented in Table 3 . The odds ratios suggest that people show a preference for lower fees and that the strength of this preference increases as the fee level increases. A preference for senior staff was strong and people also showed something of a preference for flexibility in the teaching platform. Having carte blanche to choose all degree modules was not important to people, which was somewhat surprising as our qualitative findings suggest that people chose the London School of Hygiene \& Tropical Medicine because of the applicability and uniqueness of the courses. Finally, people showed a strong disfavour for the duration of the course to be extended to a possible five years. On the other hand there was no strong desire to choose the two-year part time option over a oneyear full time degree (odds ratios close to 1, and non-significant). It is possible however that people did not fully understand the five-year attribute and thought that it would require five 
years and not as an optional extension of up to five years. Overall these results are not too surprising and largely reflect preferences in keeping with what the qualitative data suggest, which further offers reassurance of face validity.

Table 3: Odds ratios associated with choosing each level of the attribute from a conditional logit model with standard errors and p-values.

\begin{tabular}{lrrr}
\hline Attribute & $\begin{array}{r}\text { Odds } \\
\text { ratio }\end{array}$ & Std. error & p-value \\
\hline Fees at $£ 12,000$ (ref: $£ 9,000)$ & & & \\
Fees at $£ 15,000$ (ref: $£ 9,000)$ & 0.81 & 0.04 & $<0.0001$ \\
Senior staff (ref: junior staff) & 0.55 & 0.03 & $<0.001$ \\
Mixed classroom \& remote learning (ref: classroom only) & 1.75 & 0.07 & $<0.001$ \\
Choose all modules (ref: only some choice) & 1.18 & 0.04 & $<0.001$ \\
Part time two yrs (ref: fulltime, one yr) & 0.99 & 0.04 & 0.737 \\
Part time, up to five yrs (ref: fulltime, one yr) & 0.96 & 0.05 & 0.462 \\
Constant & 0.44 & 0.02 & $<0.001$ \\
& 1.07 & 0.05 & 0.143
\end{tabular}

To examine whether there were differences in preferences between demographic subgroups, we tested all possible interactions between the five attributes and gender, employment status and age group. Table 4 shows the model with all significant interactions retained. Gender interacts with fees only, and both age group and employment status interact with the duration of the course. Although both age group and employment status significantly interacted with course duration, it is likely that these two variables are largely picking up on the same people. A cross-tabulation showed that there are only eight individuals who are students in the over 30 group but those in the 18 to 30 age group are a mixture of 60 employed and 51 students. Due to this collinearity, we retained only the gender and employment status interaction. The odds ratios for the interaction terms cannot be interpreted as they appear in the model, so to illustrate exactly how these two interactions work, we present the models for these subgroups separately. The results of these models are given in Tables 5 and 6 respectively.

Table 4: full model with all significant interactions included.

\begin{tabular}{lrrr}
\hline Attribute & $\begin{array}{c}\text { Odds } \\
\text { ratio }\end{array}$ & Std. error & p-value \\
\hline Fees at $£ 12,000$ (ref: 9,000) & 0.90 & 0.06 & 0.108 \\
Fees at 115,000 (ref: 9,000) & 0.63 & 0.05 & $<0.001$ \\
Senior staff (ref: junior staff) & 1.82 & 0.08 & $<0.001$ \\
Mixed classroom \& remote learning (ref: classroom only) & 1.14 & 0.05 & 0.001 \\
Choose all modules (ref: only some choice) & 1.00 & 0.04 & 0.928 \\
Part time two yrs (ref: fulltime, one yr) & 0.99 & 0.09 & 0.925 \\
Part time, up to five yrs (ref: fulltime, one yr) & 0.42 & 0.04 & $<0.001$ \\
Student*part time two yrs (ref: employed) & 0.68 & 0.09 & 0.002 \\
Student*part time five yrs (ref: employed) & 0.54 & 0.07 & $<0.001$ \\
Age 30plus*part time two yrs (ref: 18 to 30 yrs) & 1.27 & 0.15 & 0.047 \\
Age 30plus*part time five yrs (ref: 18 to 30 yrs) & 1.51 & 0.18 & 0.001 \\
Female*fees (ref: male) & 1.00 & 0.00 & 0.030 \\
Constant & 1.04 & 0.05 & 0.433 \\
\hline
\end{tabular}


When the preferences of the two sexes are modelled separately (Table 5), the nature of the fees interaction becomes apparent. Women exhibit significantly less desire to increase fees from $£ 9,000$ to $£ 12,000$ while men also express less desire for $£ 12,000$, compared to $£ 9,000$ this difference is not statistically significant. Both sexes find the shift to $£ 15,000$ fees strongly undesirable. We can also see that men are less concerned about the teaching platform than women are; women prefer the flexibility of the teaching medium to a traditional classroom setting.

Table 5: Preferences for attributes by gender

\begin{tabular}{|c|c|c|c|c|c|c|}
\hline Attribute & $\begin{array}{l}\text { Men } \\
\text { Odds } \\
\text { ratio } \\
\end{array}$ & Std. error & p-value & $\begin{array}{l}\text { Women } \\
\text { Odds } \\
\text { ratio }\end{array}$ & Std. error & p-value \\
\hline Fees at $£ 12,000$ & 0.86 & 0.07 & 0.072 & 0.78 & 0.06 & $<0.001$ \\
\hline Fees at $£ 15,000$ & 0.62 & 0.05 & $<0.001$ & 0.49 & 0.04 & $<0.001$ \\
\hline Senior staff & 1.65 & 0.10 & $<0.001$ & 1.86 & 0.10 & $<0.001$ \\
\hline Mix class \& remote & 1.11 & 0.06 & 0.063 & 1.22 & 0.06 & $<0.001$ \\
\hline Choose all modules & 0.99 & 0.06 & 0.918 & 0.99 & 0.05 & 0.863 \\
\hline Part time two yrs & 0.92 & 0.08 & 0.297 & 1.01 & 0.08 & 0.929 \\
\hline Part time five yrs & 0.42 & 0.03 & $<0.001$ & 0.45 & 0.03 & $<0.001$ \\
\hline Constant & 1.07 & 0.07 & 0.302 & 1.07 & 0.06 & 0.237 \\
\hline
\end{tabular}

For employment status (Table 6), there are a few interesting differences in the preferences expressed by students and those who are working. Students do not show a significant preference between $£ 9,000$ and $£ 12,000$ while employed people do, possibly reflecting different valuations of money between these two groups (current students are likely to already be in debt and accustomed to borrowing, or others paying, whereas those in employment may be more likely to self-finance or have other commitments, such as a mortgage, family, etc.). Both groups however still expressed a strong rejection of the $£ 15,000$ fee band. Students preferred full time over both of the part time options while employed people did not express a clear favourite between full time and the two-year part time option. Neither group preferred the five-year option.

Table 6: Preference for attributes by employment status

\begin{tabular}{llrrrrr}
\hline Attribute & $\begin{array}{l}\text { Employed } \\
\text { Odds } \\
\text { ratio }\end{array}$ & $\begin{array}{c}\text { Std. } \\
\text { error }\end{array}$ & p-value & $\begin{array}{l}\text { Student } \\
\text { Odds } \\
\text { ratio }\end{array}$ & Std. error & p-value \\
\hline Fees at £12,000 & & & & & & \\
Fees at £15,000 & 0.77 & 0.05 & $<0.001$ & 1.05 & 0.11 & 0.652 \\
Senior staff & 0.52 & 0.04 & $<0.001$ & 0.61 & 0.07 & $<0.001$ \\
Mix class \& remote & 1.84 & 0.09 & $<0.001$ & 1.69 & 0.13 & $<0.001$ \\
Choose all modules & 1.18 & 0.06 & $<0.001$ & 1.08 & 0.08 & 0.312 \\
Part time two yrs & 1.00 & 0.05 & 0.936 & 1.00 & 0.07 & 0.946 \\
Part time five yrs & 1.13 & 0.08 & 0.093 & 0.67 & 0.07 & $<0.001$ \\
Constant & 0.53 & 0.04 & $<0.001$ & 0.24 & 0.03 & $<0.001$ \\
& 1.00 & 0.06 & 0.986 & 1.14 & 0.10 & 0.133 \\
\hline
\end{tabular}




\section{Willingness to pay}

Perhaps the most revealing thing that a discrete choice experiment can show is the monetary value of the attributes in terms of how much one is 'willing to pay' for certain attributes, trading off others. Table 7 shows the willingness to pay coefficients (in Pounds Sterling) and 95 per cent confidence intervals for the monetary trade-off value for each attribute; first for the overall model (including everyone) and then broken down by gender and employment status.

Table 7: Willingness to pay. Lower and upper refer to the bounds of the $95 \%$ confidence intervals

\begin{tabular}{lrrr}
\hline Attribute & WTP $(\mathfrak{E})$ & lower & upper \\
\hline & & & \\
Senior staff (ref: junior staff) & 5637.75 & 4444.63 & 6830.87 \\
Mixed classroom \& remote learning (ref: classroom only) & 1726.95 & 949.82 & 2504.07 \\
Choose all modules (ref: only some choice) & -88.32 & -823.75 & 647.12 \\
Part time two yrs (ref: full time, one yr) & -199.44 & -1263.75 & 864.86 \\
Part time, up to five yrs (ref: full time, one yr) & -8001.66 & -9738.64 & -6264.68 \\
& & & \\
\hline
\end{tabular}

Tables 7,8 and 9 largely tell the same story as the conditional logit models. Overall, people are willing to pay most highly for staff expertise $(£ 5,637.75)$ and to pay the least for the fiveyear potential duration of the course; in fact they would prefer to be compensated by $£ 8,001.66$ to utilise this option! The only other significant finding is that people are willing to pay $£ 1,676.56$ for the flexibility of having both classroom taught and remote learning options. When the willingness to pay models are split by gender and by employment status the trend is almost identical, albeit with different values depending on the demographic. The only exception is for students who show a preference for full time study and would need to be compensated by $£ 2,837.97$ to choose the two-year part-time option. It is possible that this may be because current students want to complete their studies sooner, whereas people in employment might be less concerned about part-time study if it meant they could retain some level of income.

Table 8: Willingness to pay by gender. Lower and upper refers to the bounds of the $95 \%$ confidence intervals.

\begin{tabular}{lrrrrrr}
\hline Attribute & \multicolumn{1}{l}{$\begin{array}{c}\text { Men } \\
\text { WTP }(\mathfrak{f})\end{array}$} & lower & upper & $\begin{array}{r}\text { Women } \\
\text { WTP }(\mathfrak{f})\end{array}$ & lower & upper \\
\hline & & & & & & \\
Senior staff & 6254.30 & 3802.76 & 8705.84 & 5242.30 & 3951.29 & 6533.30 \\
Mix class \& remote & 1676.56 & 201.30 & 3151.82 & 1916.69 & 1017.40 & 2815.97 \\
Choose all modules & -173.97 & -1570.09 & 1222.14 & -118.51 & -959.58 & 722.56 \\
Part time two yrs & -1067.41 & -3043.63 & 908.80 & 123.29 & -1111.14 & 1357.73 \\
Part time five yrs & -10583.52 & -14655.92 & -6511.11 & -6606.34 & -8352.19 & -4860.48 \\
& & & & & & \\
\hline
\end{tabular}


Table 9: Willingness to pay by employment status. Lower and upper refers to the bounds of the $95 \%$ confidence intervals

\begin{tabular}{lrrrrrr}
\hline Attribute & $\begin{array}{c}\text { Employed } \\
\text { WTP }(\mathfrak{\xi})\end{array}$ & lower & upper & $\begin{array}{r}\text { Student } \\
\text { WTP }(\mathfrak{\xi})\end{array}$ & lower & upper \\
\hline & & & & & & \\
Senior staff & 5362.00 & 4112.35 & 6611.66 & 5618.88 & 3435.90 & 7801.85 \\
Mix class \& remote & 1918.80 & 1056.95 & 2780.66 & 1999.66 & 557.58 & 3441.74 \\
Choose all modules & -109.30 & -908.96 & 690.36 & -313.48 & -1658.16 & 1031.20 \\
Part time two yrs & 869.32 & -351.61 & 2090.25 & -2837.97 & -4784.61 & -891.32 \\
Part time five yrs & -5467.79 & -6976.79 & -3958.80 & -12143.96 & -16496.26 & -7791.66 \\
& & & & & & \\
\hline
\end{tabular}

\section{Summary and conclusions}

The attribute that people showed the strongest preference for was staff expertise. This applies to both sexes, as well as students and workforce employees. Another attribute that came across as important was the option to have some courses available by remote learning as well as classroom taught, although more so for women. Although the top level fees were an unsurprising repellent, the difference between the two lower fee levels was not as important as one might think, especially for student and male subgroups. Finally the idea of extending the part-time course to up to five years was not preferred by any demographic. It is possible that this question was misinterpreted, although it is not necessarily an irrational choice either. Promoting the reputation of the School's teaching staff and providing more flexibility in the teaching platform are two things that these findings suggest that the School should continue to invest in.

This study demonstrates that discrete choice experiments can reveal much more about student decision-making and student demand than conventional descriptive survey methods can. Specifically, discrete choice models can estimate the relevant importance of the attributes and the monetary amount that students are willing to trade off between attributes. For example, descriptive data from our example suggested that the uniqueness of the courses offered at the School was important to potential students; however the results from the discrete choice experiment show that this attribute is less important than the teaching staff expertise. In fact it appears that there is no reason to make the courses 100 per cent flexible in terms of module choice. On the other hand, while this was not often mentioned in the student surveys, the flexibility of the teaching platform (combined classroom teaching and remote, online learning) came up as relatively important in the discrete choice experiment. This provides policy-makers at the School with compelling evidence for increasing the flexibility of the modes of teaching available and promoting the reputation of the teaching staff. More broadly, we have demonstrated how higher educational institutions can apply this method to their own degree programs to estimate student demand, tailored to the specific needs of their student market.

Higher education enrolment has fallen in the UK (Universities UK, 2013) meaning that determining student demand is ever more important if universities are to remain competitive. We recommend that discrete choice experiments can usefully be applied to many different types of educational institutes and can reveal much more precise information about what students want than commonly used descriptive data can.

\section{Acknowledgements}


We would like to thank John Edmunds, Susie Schaffnit, and Nadia Chan of the London School of Hygiene \& Tropical Medicine for their assistance and helpful comments. This study was supported by LSHTM internal funding. The authors declare no conflicts of interest.

\section{References}

Bridges, J. F. P., Hauber, B., Marshall, D., Lloyd, A., Prosser, L., Regier, D., ... Mauskopf, J. (2011). Conjoint analysis applications in health--a checklist: a report of the ISPOR Good Research Practices for Conjoint Analysis Task Force. Value in Health, 14(4), 403-13. doi:10.1016/j.jval.2010.11.013

Chomitz, K., Setiadi, G., Azwar, A., \& Wadiyarti, N. (1999). What Do Doctors Want? Developing Incentives for Doctors to Serve in Indonesia's Rural and Remote Areas (pp. $1-43)$.

Coast, J., \& Horrocks, S. (2007). Developing attributes and levels for discrete choice experiments using qualitative methods. Journal of Health Services Research \& Policy, 12(1), 25-30. doi:10.1258/135581907779497602

Department for Business Information and Skills. (2011). Higher Education: Students at the Heart of the System. London: Crown.

Earnhart, D. (2002). Combining Revealed and Stated Data to Examine Housing Decisions Using Discrete Choice Analysis. Journal of Urban Economics, 51(1), 143-169. doi:10.1006/juec.2001.2241

Elliott, K. M., \& Shin, D. (2002). Student Satisfaction: an alternative approach to assessing this important concept. Journal of Higher Education Policy and Management, 24(2), 197-209. doi:10.1080/136008002200001351

Hensher, D., Rose, J. M., \& Greene, W. (2005). Applied choice analysis: a primer (p. 717). New York: Cambridge University Press.

Kjaer, T., Bech, M., Gyrd-Hansen, D., \& Hart-Hansen, K. (2006). Ordering effect and price sensitivity in discrete choice experiments: need we worry? Health Economics, 15(11), 1217-28. doi:10.1002/hec. 1117

Kløjgaard, M. E., Bech, M., \& Søgaard, R. (2012). Designing a Stated Choice Experiment: The Value of a Qualitative Process. Journal of Choice Modelling, 5(2), 1-18. doi:10.1016/S1755-5345(13)70050-2

Kolstad, J. R. (2011). How to make rural jobs more attractive to health workers. Findings from a discrete choice experiment. Health Economics, 211 (January 2010), 196-211. doi: $10.1002 / \mathrm{hec}$

Kruk, M. E., Johnson, J. C., Gyakobo, M., Agyei-Baffour, P., Asabir, K., Kotha, S. R., ... Dzodzomenyo, M. (2010). Rural practice preferences among medical students in Ghana: a discrete choice experiment. Bulletin of the World Health Organization, 88(5), 333-41. doi:10.2471/BLT.09.072892 
Kuhfeld, W. F. (2010). Marketing research methods in SAS. Cary NC: SAS Institute Inc.

Louviere, J., Hensher, D., \& Swait, J. (2000). Stated Choice Models: analysis and application (p. 402). Cambridge, UK: Cambridge University Press.

Mellors-bourne, R., Hooley, T., \& Marriott, J. (2014). Understanding how people choose to pursue taught postgraduate study Report to HEFCE by CRAC and iCeGS.

Orme, B. (2010). Sample Size Issues for Conjoint Analysis. In Getting Started with Conjoint Analysis (pp. 57-66). Madison, Wis.: Research Publishers LLC.

Peterson, R., \& Wilson, W. (1992). Measuring customer satisfaction: Fact and artifact. Journal of the Academy of Marketing Science, 20(1), 61-71. doi:10.1007/BF02723476

Universities UK. (2013). The funding environment for universities: an assessment.

World Health Organization. (2012). How to Conduct a Discrete Choice Experiment for Health Workforce Recruitment and Retention in Remote and Rural Areas: A user guide with case studies. Geneva. 